Jurdimas (Jurnal Pengabdian Kepada Masyarakat) Royal

Vol. 5 No. 1, Januari 2022, hlm. 39 - 44

Available online at https:/jurnal.stmikroyal.ac.id/index.php/jurdimas

\title{
PENGEMBANGAN WEBSITE UNTUK PENGELOLAAN BUMDES DESA CIPTA KARYA, BENGKAYANG
}

\author{
Yuliana $^{1^{*}}$, Santi Thomas ${ }^{1}$, Adri Priadana ${ }^{2}$ \\ ${ }^{1}$ Teknologi Informasi, Institut Shanti Bhuana \\ ${ }^{2}$ Informatika, Universitas Jenderal Achmad Yani Yogyakarta \\ email: *yuliana@shantibhuana.ac.id
}

\begin{abstract}
Community service activities aimed at the government of Cipta Karya Village, Sungai Betung District, Bengkayang Regency aim to increase the interest and use of Information Technology in the Website field. Through a village institution managed by the community and village government, namely BUMdes, this greatly helps the community in improving the village economy which has the potential for information that can be used to convey information. Utilization of Information Technology in the creation of the assisted village web to display information related to the activities of the creation village. The service was carried out by studying the literature, implementing and evaluating. Where the implementation is carried out in stages such as socialization, data management, creation of websites and domains as well as admin training, to management of village websites. Through this website, the village government can provide information related to village activities such as potential tourism objects.
\end{abstract}

Keywords: BUMDES; management; website development; village

\begin{abstract}
Abstrak: Kegiatan pengabdian pada masyarakat dengan sasaran pemerintah Desa Cipta Karya Kecamatan Sungai Betung Kabupaten Bengkayang bertujuan untuk meningkatkan minat dan pemanfaatan Teknologi Informasi pada bidang Website. Desa Cipta Karya belum memiliki wadah atau tempat untuk mempromosi potensi wisata desa. Pengelolaan Bumdes belum dimanfaatkan dengan baik dan benar dan belum ada tempat untuk menginformasi kegiatan atau informasi yang ada di Desa. Begitu pula peta lokasi wisata belum banyak diketahui oleh masyarakat luar. Melalui sebuah lembaga Desa yang dikelola oleh masyarakat dan pemerintah desa yaitu BUMdes, ini sangat membantu masyarakat dalam meningkatkan perekonomian desa yang memiliki potensi informasi yang bisa digunakan untuk menyampaikan suatu informasi. Pemanfaatan Teknologi Informasi dalam pembuatan web desa binaan untuk menampilkan informasi yang berkaitan dengan kegiatan desa cipta karya. Pengabdian ini dilakukan dengan metode studi literatur, pelaksanaan dan evaluasi. Dimana pada pelaksanaannya dilakukan tahap seperti sosialisasi, pengumpulan data, pembuatan website dan domain dan juga pelatihan admin, hingga pengelolaan website desa. Melalui website ini, pihak pemerintah desa dapat memberikan informasi terkait dengan kegiatan desa seperti potensi objek wisata.
\end{abstract}

Kata kunci: BUMdes; desa; pengelolaan; pengembangan website 
Jurdimas (Jurnal Pengabdian Kepada Masyarakat) Royal

Vol. 5 No. 1, Januari 2022, hlm. 39 - 44

Available online at https:/jurnal.stmikroyal.ac.id/index.php/jurdimas

\section{PENDAHULUAN}

Perkembangan teknologi Informasi pada zaman digitalisasi yang serba terhubung melalui jaringan internet. Seperti saat ini begitu cepat dan mudah dalam mengetahui informasi juga membutuhkan teknologi, apalagi berbicara mengenai informasi sebuah desa yang sangat minim dan tertinggal dalam memanfaatkan teknologi informasi. Teknologi Informasi adalah berbagai teknologi dan aplikasi komputer untuk menyimpan, mempelajari, menganalisa, mengambil, memanipulasi data dan atau informasi dalam bentuk kata-kata, suara (audio/video), dokumen dan atau gambar-gambar serta mengirimkan/ mendistribusikan, menerima dan mengolah/memproses kembali sesuai dengan kebutuhan pemakai/ pengguna informasi secara elektonik (Bagaskoro, 2019).

Salah satu teknologi informasi yang berkembang saat ini adalah website, hal ini dapat dilihat dari banyaknya masyarakat yang menggunakan fasilitas website sebagai pemanfaatan dalam mengakses untuk mempromosi kegiatan mereka. Website merupakan sebuah media yang memiliki banyak halaman yang saling terhubung (hyperlink), dimana website memiliki fungsi dalam memberikan informasi berupa teks, gambar, video, suara dan animasi atau penggabungan dari semuanya.

Karakteristik yang dimiliki oleh website adalah halaman-halaman yang saling terhubung, dan dilengkapi dengan domain sebagai alamat (url) atau world wide web (www) dan juga hosting sebagai media yang menyimpan banyak data. Website dapat diakses menggunakan jaringan internet dengan platform yang disebut browser (Elgamar, 2020).
Desa merupakan salah satu
tempat yang berpotensi untuk perekonomian negara. Badan Usaha Milik Desa yang disebut BUMDes. Melalui sebuah lembaga desa yang dikelola oleh masyarakat dan pemerintah desa yaitu BUMDes tersebut dengan tujuan untuk memperkuat perekonomian desa dan dibentuk berdasarkan kebutuhan dan potensi yang ada di desa (MY, 2019). Salah satu BUMDes yang didirikan pada tahun 2020 diberi nama BUMDes Panyanggar.

Melalui lembaga BUMDes ini sangat membantu masyarakat dalam meningkatkan perekonomian desa. Banyak sekali potensi informasi yang bisa digunakan untuk menyampaikan suatu informasi. Salah satu contohnya adalah Potensi wisata yang dimiliki suatu wilayah dan belum dilakukan penyampaian secara baik dan benar, maka tidak akan dikenal banyak orang jika tidak dipublikasi.

Desa Cipta Karya merupakan salah satu desa yang berada di Kabupaten Bengkayang dengan jumlah penduduk mencapai 3.853 jiwa, 1.954 laki-laki dan 1.899 perempuan (Data Penduduk bulan Januari 2021). Desa Cipta Karya adalah sebuah desa yang memiliki potensi objek wisata yang bisa digunakan sebagai potensi untuk menambah penghasilan desa. Desa Cipta karya ini tidak jauh dari pasar Bengkayang, sebuah desa kecil yang memiliki tempat wisata-wisata alam yang sangat menarik untuk hiburan masyarakat. Wisata alam yang dimiliki antara lain: Bukit sepadang spot 2 (Sepancong), Bukit salapar Batu Bide, Bukit Pejamet Riam Palayo. (Kalvin, 2021) 


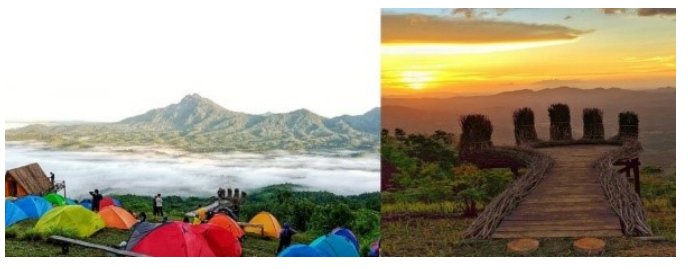

(a)

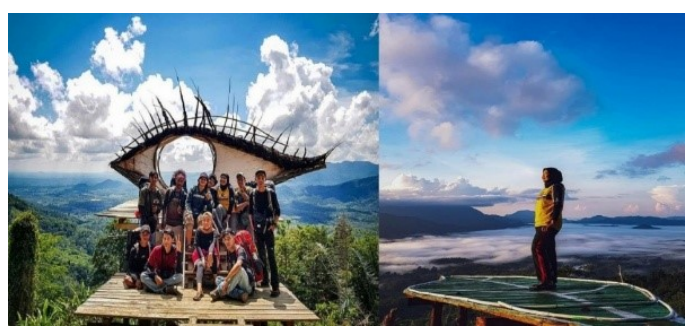

(b)

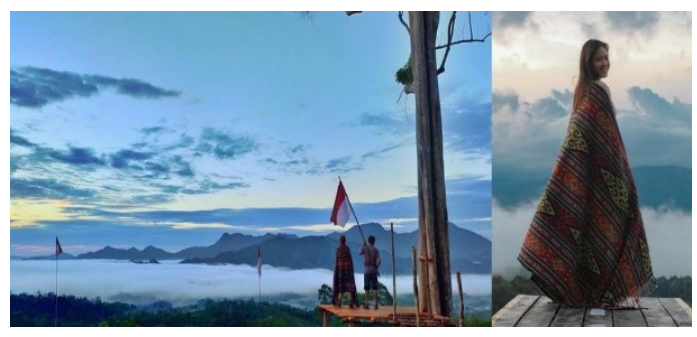

(c)

Gambar 1. Potensi Objek Wisata Desa Cipta Karya (a) Sepadang hill (b) Bukit Pajamet (c) Bukit Salapar

Untuk mendukung eksistensi wisata alam yang dimiliki Desa Cipta Karya, maka perlu berbenah agar mengikuti perkembangan yang serba memanfaatkan teknologi informasi berupa website desa. Website desa belum dimiliki oleh desa cipta karya yang nantinya website desa ini dibuat dan di onlinekan dengan tujuan masyarakat desa juga perlu mendapatkan informasi dalam setiap perkembangan, sehingga dapat memenuhi kebutuhan serta mendapatkan manfaat dalam kegiatan perekonomian maupun yang lainnya. Dengan memanfaatkan platform wordpress dilakukanlah pengembangan teknologi informasi yaitu website yang tujuannya mempermudah masyarakat luar untuk mengetahui potensi alam Desa Cipta Karya ini dengan menampilkan potensi dan keunggulan wisata alam, serta memberi informasi peta lokasi wisata dan informasi lainnya. Untuk itu perlu dikembangkan usaha perekonomian dan pengolahan potensi sesuai dengan kebutuhan masyarakat agar menjadi tulang punggung pertumbungan perekonomian pedesaan. Melalui BUMdes desa, harapannya dapat membantu dalam pengelolaan website desa sebagai produk usaha desa dalam mengembangkan kemajuan desa melalui Teknologi Informasi.

\section{METODE}

Adapun mitra dalam pengabdian ini yaitu BUMDes desa Cipta Karya. Metode pengabdian ini dilakukan melalui dipusi iptek dengan memanfaatkan platform wordpress sebagai pengola website desa. Wordpress adalah sebuah aplikasi open source Content Management System (CMS) yang dapat digunakan secara gratis dan bebas untuk dimodifikasi sesuai dengan keinginan pengguna. Wordpress juga menyediakan plugin yang memudahkan pengguna untuk menambah fitur pada website (Mubarok, 2018). Metode kegiatan pengabdian terdiri dari 3 tahapan, yaitu melalui Studi literatur, Pelaksanaan, Sosialisasi dan Pengumpulan data.

\section{Studi literatur}

Pelaksanaan berupa analisis situasi, pemetaan permasalahan yang kemudian diselesaikan, pengusulan pendapat dan solusi, target luaran dan kebutuhan sumber daya manusia, penyusunan rencana kerja, jadwal pelaksanaan, serta observasi. 
Available online at https://jurnal.stmikroyal.ac.id/index.php/jurdimas

\section{Pelaksanaan}

Pelaksanaan kegiatan pengabdian terdiri dari 4 tahap, seperti terlihat pada gambar sebagai berikut;

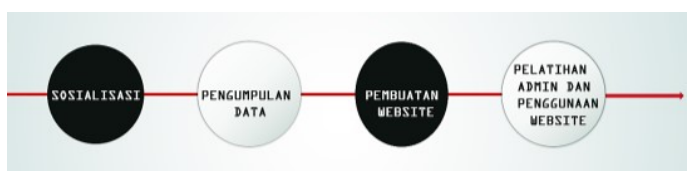

Gambar 2. Tahapan Pelaksanaan Pengabdian

\section{Sosialisasi}

Kegiatan ini untuk mensosialisasikan kepada pemerintah desa tentang kegiatan pengabdian, jadwal pelaksanaan, kegiatan yang dilakukan seperti mengkoordinasi pengumpulan profil desa, pelatihan penggunaan website. Sosialisasi ini dilaksanakan di kantor desa dihadiri oleh pemerintah desa seperti kepala desa dan kasi desa.

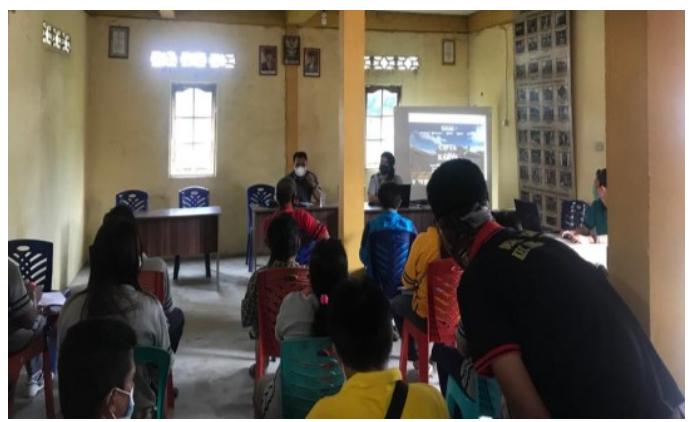

Gambar 3. Sosialisasi Web Desa

\section{Pengumpulan data}

Dengan tujuan sebagai bahan informasi atau konten website. Data yang terkumpul seperti profile desa, tentang desa, demografi desa, sejarah desa, foto objek wisata, kontak. Data-data ini akan ditampilkan pada website desa. Proses ini dilakukan selama 2 bulan.

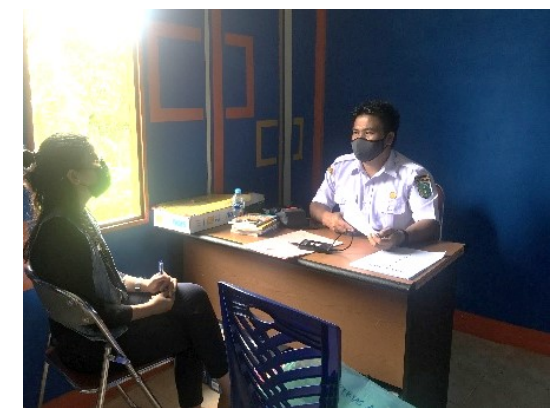

Gambar 4. Koordinasi dalam mengumpulan data desa

\section{PEMBAHASAN}

\section{Pembuatan website dan domain}

Pembuatan website dengan memanfaatkan platform Wordpress yang diberi alamat domain desaciptakarya.id. Berikut adalah langkah-langkah yang perlu dilakukan dan dipersiapkan dalam membuat website melalui paltform wordpress yaitu: (1) Instal wordpress, dengan login ke member area, (2) Mengelola dashboard dilakukan melihat dan mengedit fitur-fitur wordpress, (3) Memilih tema yang menarik lalu diinstal kedalam platform wordpress, (4) Instal plugin, bertujuan untuk meningkatkan kinerja wordpress, (5) Mengupload berita kegiatan pada editor dengan cara memilih New $\rightarrow$ post, (6) Membuat halaman wordpress, tujuannya untuk mengubah urutan halaman yang sesuai dan menggabungkan beberapa halaman.

\section{Pelatihan admin}

Pelatihan dalam menggunakan wordpress, dilakukan di kantor desa cipta karya dengan melatih bagian kasi pemerintah yaitu Bapak Hendra yang ditunjukan sebagai administrator website desa oleh Kepala Desa. 


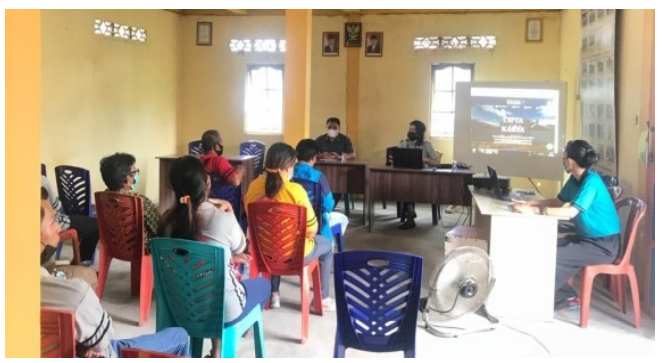

Gambar 5. Pelatihan admin dan penjelasan manfaat Web Desa

\section{Evaluasi}

Tahapan terakhir dilaksanakan dengan tujuan untuk melakukan perbaikan pada proses pengabdian yang sedang berjalan dan perbaikan untuk kegiatan pengabdian berikutnya. Proses evaluasi ini tujuannya untuk memudahkan proses perkembangan website yang akan datang. Dan melakukan koordinasi dengan para pemerintah desa sebagai monitoring kegiatan pengabdian. Hasil evaluasi ditulis dalam laporan pengabdian sebagai dasar untuk perbaikan kegiatan pengabdian selanjutnya.

Pembuatan website desa Cipta Karya dengan domain (desaciptakarya.id), menampilkan informasi profil desa, berita desa, galeri desa, kontak, setiap halaman ditampilkan form chatt untuk bisa komunikasi melalui chatting WhatsApp.

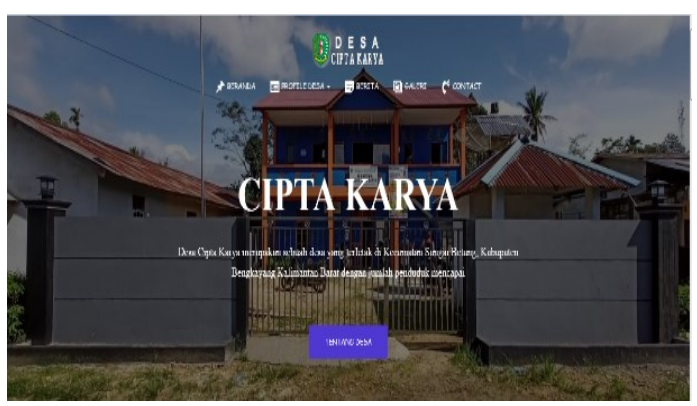

Gambar 6. Tampilan Utama website desa Cipta Karya.

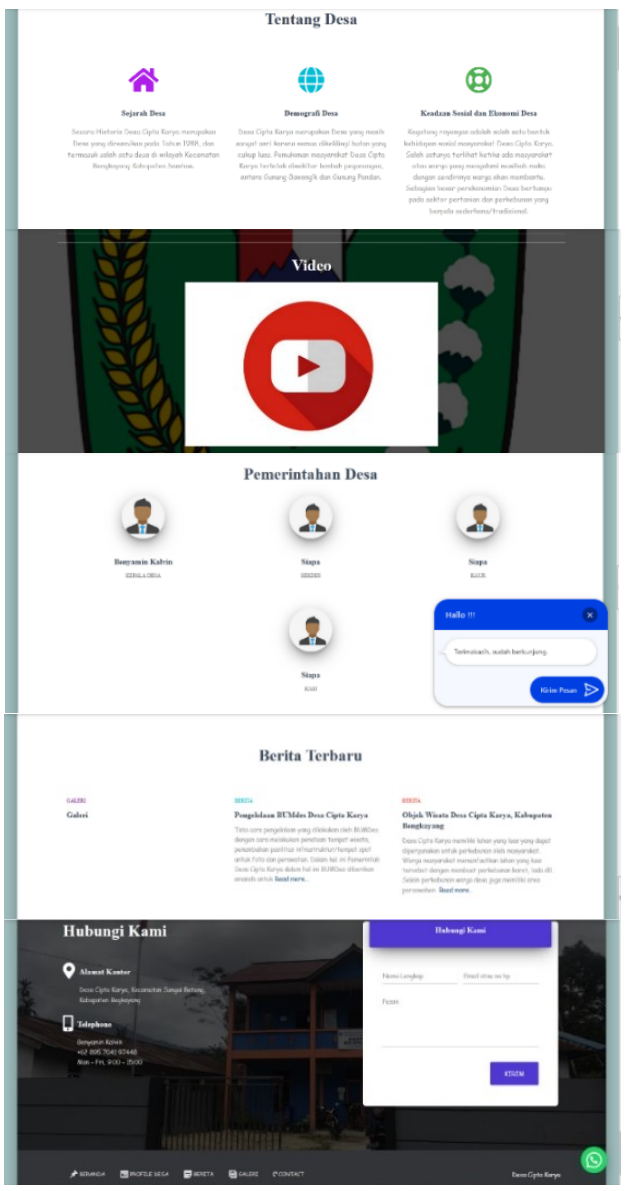

Gambar 7. Tampilan website desa Cipta Karya.

Tampilan website ini terdiri dari menu sebagai berikut: (1) Beranda, berisi halaman muka yang terdiri dari informasi tentang desa, video desa, lembaga desa, berita terbaru dan kontak dan form chatt whatsapp. (2) Profile desa terdiri dari sub menu yaitu tentang desa, sejarah desa, demografi desa dan lembaga desa. (3) Pada menu sub desa Tentang desa berisi tentang penjelasan desa dan keadaan sosial dan ekonomi desa. (4) Berita berisi berita desa mengenai kegiatan desa dan potensi objek wisata desa yang telah terlaksanakan. (5) Galeri berisi album atau foto-foto kegiatan desa. (6) Kontak berisi alamat dan peta desa. 
Jurdimas (Jurnal Pengabdian Kepada Masyarakat) Royal

Vol. 5 No. 1, Januari 2022, hlm. 39 - 44

ISSN 2614-7912 (Print)

DOI: https://doi.org/10.33330/jurdimas.v5i1.1200

ISSN 2622-3813 (Online)

Available online at https:/jurnal.stmikroyal.ac.id/index.php/jurdimas

\section{SIMPULAN}

Setelah melaksanakan pengabdian website desa cipta karya kecamatan sungai betung kabupaten bengkayang, dengan luaran sebuah website yaitu linknya www.ciptakarya.id pemerintah desa dapat menampilkan profil desa, kegiatan desa dan aktivitas yang perlu di publikasikan kepada masyarakat umum melalui web. Melalui website desa ini, sangat membantu publikasi perkembangan desa terutama pada potensipotensi wisata yang terdapat di desa cipta karya. Salah satu pemerintah desa yang bertugas sebagai admin untuk mengelola website telah diberikan pelatihan mengenai cara penggunaan website. Harapannya agar pemerintah desa dapat melakukan kesediaan kepada salah satu staf desa yang bertanggung jawab penuh untuk mengelola website dan juga dibutuhkan infrastruktur yang dapat membantu proses pengelolaan website, serta perlunya ada pelatihan lebih lanjut dalam menulis berita yang menarik terutama tentang potensi-potensi kegiatan dan objek wisata desa dalam mengisi konten untuk website.

\section{DAFTAR PUSTAKA}

Afandi, A., Mintoro, S., \& Indah Sari, Y. (2020). Rancang Bangun Sistem Informasi Badan Usaha Milik Desa (BumDes) Berbasis Web Mobile. Jurnal Sistem Informasi Dan Manajemen Basis Data (SIMADA), 03(01), 23-31.

Bagaskoro. (2019). Pengantar Teknologi Informasi Informatika dan Komunikasi data. CV. Budi Utama.
Elgamar. (2020). Konsep Dasar Pemrograman Website dengan PHP (N. Pangesti (ed.)). CV. Multimedia Edukasi.

Fattah, F. (2020). Pemanfaatan Website Sebagai Media Penyebaran Informasi Pada Desa Tonasa Kecamatan Sanrobone Kabupaten Takalar. Ilmu Komputer Untuk Masyarakat, 1(1),16-21.

https://ilkomas.id/index.php/ilk omas/article/view/5

Kalvin, B. (2021). Profil Desa Cipta Karya.

Mubarok, I. (2018). Apa Itu WordPress? Pengertian WordPress dan Manfaatnya. In Https://Www.Niagahoster.Co.Id /(p.1).https://www.niagahoster.c o.id/blog/apa-itu-wordpress/

MY. (2019). MEMAHAMI APA ITU BADAN USAHA MILIK DESA ?Accounting.InAccounti ng.Binus.Ac.Id.https://accountin g.binus.ac.id/2019/12/27/mema hami-apa-itu-badan-usahamilik-desa/

Putra, G. B., \& Atmaja, E. J. J. (2021). Pedampingan Penggunaan Sistem Informasi Profil Desa Banyuasin Berbasis Internet Dan Aplikasi Mobile. Jurdimas (Jurnal Pengabdian Kepada Masyarakat) Royal, 4(1), 97102.

Wiguna, I. K. A., \& Ariana, K. A. (2021). Rancangan Model Digitalisasi Pasar Tradisional Pasar Rare Angon Di Desa Gunaksa. Jurdimas (Jurnal Pengabdian Kepada Masyarakat) Royal, 4(3), 257-262. 